\title{
Implicações da imunossenescência na vacinação de idosos
}

\author{
Implications of immunosenescence in vaccination of the elderly
}

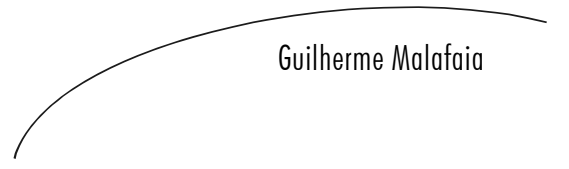

\section{Resumo}

A prevalência de indivíduos idosos em relação aos indivíduos jovens compreende um quadro comum na população mundial. Estima-se que, em 2050, cerca de $22 \%$ da população mundial será constituída por indivíduos idosos. No Brasil, o número de idosos ( $\geq 60$ anos de idade) passou de 3 milhões em 1960 para 7 milhões em 1975 e 14 milhões em 2002 (um aumento de 500\% em 40 anos), e estima-se que alcançará 32 milhões em 2020. Este fenômeno se deve ao advento de drogas antibacterianas, a vacinações em larga escala e a outros avanços no tratamento médico. Contudo, a eficácia de uma vacina depende, sobretudo, da habilidade dos indivíduos para exibir uma resposta imune adequada. Assim, esta revisão apresenta os principais efeitos da imunossenescência na resposta imune a uma vacina. Além disto, discute algumas estratégias que aumentam os níveis de proteção das imunizações neste grupo etário. A compreensão dos fatores envolvidos na geração de uma resposta imunológica durante a senescência e a introdução de estratégias que melhoram a eficácia de vacinas nos indivíduos idosos reduz a incidência e a severidade de doenças infecciosas, tendo forte im-

Palavras-chave: Envelhecimento. Sistema imune. Imunoterapia ativa. Imunização.

\section{Adjuvantes} Imunológicos. Doenças transmissíveis. Comportamento de redução do risco. Incidência. Qualidade de vida. Brasil pacto na qualidade de vida destes indivíduos.

\section{Abstract}

The increase of the elderly population is a worldwide common phenomenon. According to some projections, in the year 2050 older people will be about $22 \%$ of the world population. In Brazil the number of elderly ( $\geq 60$ years of age) increased from 3 million in 1960, and to 7 million by 1975 and 14 million by 2002 (an increase of $500 \%$ in just forty years); according to estimates, it will reach

\footnotetext{
Universidade Federal de Ouro Preto

Instituto de Ciências Exatas e Biológicas, Laboratório de Imunoparasitologia, Núcleo de Pesquisa em Ciências Biológicas Ouro Preto, MG, Brasil

Correspondência / Correspondence

Guilherme Malafaia

Rua Vereador Paulo Elias, 8A - Bauxita

35400-000 - Ouro Preto, MG, Brasil

E-mail: Guilherme@nupeb.ufop.br
} 
32 million by 2020 . This phenomenon is due to advent of antibacterial drugs, large-scale vaccinations and other advances of medical treatment. However, the vaccine efficacy depends on the ability of individuals to exhibit an adequate immune response. This review presents the main effects of immunosenescence in immune response to a vaccine. Furthermore, it discusses strategies that may counteract age-related defects in immune responses to vaccination. The understanding of how immunological memory is affected by ageing, and the introduction of strategies to ameliorate vaccine efficacy in the elderly, might reduce the incidence and the severity of infectious disease and have a strong impact on the quality of life of elderly individuals.
Key words: Ageing; Immune system. Immunotherapy active. Immunization.

Adjuvants

immunologic.

Communicable

diseases. Risk

reduction behavior. Incidence. Quality of life. Brazil

\section{INTRODUÇÃO}

O fenômeno do envelhecimento da população mundial é uma realidade que traz consigo uma série de considerações e implicações para a sociedade. Nos países industrializados, como China e Japão, e em países da Europa e da América do Norte, a população de indivíduos com idade superior a 60 anos compreende $20 \%$ da população e a proporção de indivíduos com idade superior a 85 anos cresce seis vezes mais rapidamente do que a população em geral. ${ }^{1}$

No Brasil, dados da última contagem da população, realizada em 2007 , demonstram que a pirâmide populacional, antes formada em sua maior composição por crianças, adolescentes e jovens, já apresenta um perfil aproximado do padrão vigente nos países desenvolvidos, com uma participação crescente de pessoas com mais de 50 anos nos patamares medianos e superiores de sua estrutura. ${ }^{2}$

Diante deste cenário, grandes implicações para a sociedade surgem em detrimento dos fatores e das condições relacionadas à senescência. $\mathrm{O}$ aumento da prevalência e da severi- dade das doenças infecciosas reflete inúmeras disfunções relativas à idade na resposta imune dos pacientes. Pneumonia, infecções urinárias $^{3}$ e reativação de patógenos latentes, como o vírus da varicela, ${ }^{4}$ micobactérias ${ }^{5} \mathrm{e}$ citomegalovírus, ${ }^{6}$ ocorrem freqüentemente no idoso. Nos Estados Unidos, por exemplo, a gripe causada pelo vírus da influenza e as complicações secundárias decorrentes desta doença representam a principal causa de morte em pessoas com idade superior a 65 anos. $^{7} \mathrm{Na}$ Áustria, estima-se um número entre $1.000 \mathrm{e}$ 6.000 mortes decorrentes da infecção pelo vírus da influenza, onde os indivíduos idosos e os imonocomprometidos são tidos como grupos populacionais de alto risco. ${ }^{8}$

As vacinas, rotineiramente utilizadas no mundo todo, representam grande avanço da medicina no que tange à prevenção de inúmeras doenças infecciosas e ao aumento da expectativa de vida das pessoas. Diversas campanhas de imunização têm conseguido erradicar doenças responsáveis por elevados números de morbidade e mortalidade na população idosa. A Organização Mundial da Saúde (OMS) estima que mais de dois milhões de 
mortes foram evitadas no ano de 2003, através da realização de campanhas de imunização. ${ }^{9}$ No Brasil, desde 1999 o Ministério da Saúde ${ }^{10}$ disponibiliza aos idosos a vacina contra o vírus da influen₹a, o que representa um grande benefício a este grupo etário. Dados do Ministério da Saúde indicam que mais de $70 \%$ da população idosa do país é beneficiada.

Entretanto, o desafio não se restringe apenas à necessidade de ampliar e homogeneizar as coberturas vacinais em grupos que participam menos das campanhas, mas também de se considerar que a eficácia de uma vacina depende, sobretudo, da habilidade dos indivíduos de exibir uma resposta imune adequada. A partir disto, é imprescindível o desenvolvimento de estudos que visam a descobrir estratégias que burlam os processos inerentes ao envelhecimento. Neste caso, a imunização de pessoas idosas representa uma questão de saúde pública, principalmente quando se constata que a imunossenescência afeta a resposta imune a muitas vacinas, ${ }^{11}$ o que corrobora o fato de que nem sempre vacinação é sinônimo de proteção garantida. Assim, este estudo apresenta os principais efeitos do envelhecimento na resposta a imunizações, bem como algumas estratégias recentemente adotadas, as quais podem aumentara eficiência das vacinas nos indiví- duos idosos e melhorar a qualidade de vida deste grupo etário.

\section{IMUNOSSENESCÊNCIA AFETA A RESPOSTA A VACINAS}

Embalado pela conquista da saúde pública em relação à erradicação da varíola em diversos países e apoiado pela criação do Programa Ampliado de Imunização (PAI) pela OMS, o desenvolvimento de vacinas tem proporcionado aumento da expectativa de vida das pessoas.

Diante de um cenário mundial marcado pelo crescimento da população de idosos, verifica-se considerável avanço na inovação tecnológica no desenvolvimento de vacinas. Segundo Herndler-Brandstetter et al., ${ }^{8} 26$ diferentes doenças infecciosas podem ser prevenidas através da realização de campanhas de imunização. Atualmente, diferentes tipos de vacinas têm sido desenvolvidos, cada qual com suas vantagens e, sobretudo, com características específicas. A tabela 1, estruturada com base nos trabalhos de Plotkin ${ }^{12}$ e Lambert et al. ${ }^{13}$ resume os principais tipos de vacinas atualmente disponíveis. 
Tabela 1 - Diferentes tipos de vacinas desenvolvidas atualmente. Ouro Preto, MG, 2007.

\begin{tabular}{ll}
\hline \multicolumn{1}{c}{ Categorias } & \multicolumn{1}{c}{ Características específicas } \\
\hline $\begin{array}{l}\text { Vacinas de vírus atenuados e de } \\
\text { vetores vivos }\end{array}$ & $\begin{array}{l}\text { Usualmente não são necessárias diversas doses, induzem a } \\
\text { produção de altos níveis de anticorpos e uma forte resposta de } \\
\text { linfócitos TCD8+ é verificada }\end{array}$ \\
$\begin{array}{l}\text { Vacinas com vírus inteiramente } \\
\text { inativados }\end{array}$ & Induzem a produção de altos níveis de anticorpos \\
$\begin{array}{l}\text { Vacinas conjugadas } \\
\text { Vacinas de subunidades }\end{array}$ & $\begin{array}{l}\text { Alta tolerabilidade clínica é verificada } \\
\text { Alta tolerabilidade clínica é verificada devido à pureza de um único } \\
\text { peptídeo imunogênico }\end{array}$ \\
Vacinas de DNA & $\begin{array}{l}\text { Possibilitam a manipulação específica da resposta imune celular e } \\
\text { um aumento da eficiência da resposta quando associada a vacinas } \\
\text { de subunidades } \\
\text { Alta tolerabilidade clínica é verificada, induzem a produção de altos } \\
\text { níveis de anticorpos, além de uma resposta moderada de linfócitos }\end{array}$ \\
TCD8+ \\
Vacinas de antígenos associados a
\end{tabular}

Entretanto, a influência da imunossenescência na geração de uma resposta imune eficaz a vacinas é confirmada em diversos estudos. Enquanto a vacina anti-influenza em indivíduos jovens confere de 65 a 80\% de proteção contra o vírus causador da gripe, em indivíduos idosos o nível de proteção cai para uma porcentagem de 30 a 50\%. ${ }^{14}$ Dos 31 estudos analisados por Goodwin et al., ${ }^{15}$ envolvendo a produção de anticorpos após vacinação contra o vírus da influenza, conduzidos entre os anos de 1986 e 2002, os autores constataram que todos apontam para o fato de que em idosos a resposta imune humoral é significativamente menor quando comparada à verificada em adultos jovens.

Já outros estudos focados na produção de anticorpos após vacinação contra pneumonia (causada por Streptococcus pneumoniae), hepatite $B$, encefalite, difteria e tétano têm demonstrado que a eficácia das imunizações contra estas doenças é consideravelmente reduzida nos indivíduos idosos. ${ }^{8,16-19}$

\section{BASES IMUNOLÓGICAS DA BAIXA PROTEÇÃO DAS VACINAÇÕES NOS IDOSOS}

Sabe-se que a redução da resposta imune observada durante o envelhecimento, a qual justifica os baixos níveis de proteção de diversas vacinas, está estritamente relacionada com alterações que ocorrem no timo durante a senescência. Tais alterações acabam por afetar a produção de células T, impedindo uma resposta imune eficaz ao antígeno vacinal e/ ou contra o próprio patógeno invasor. ${ }^{20} \mathrm{Du}$ rante o envelhecimento, o decréscimo da proporção de células $T$ virgens em relação às células T de memória, e o das células T maduras em relação às imaturas está, em parte, associado à involução tímica, considerada por Malaguarnera et al. ${ }^{21}$ a principal alteração ana- 
tômico-histológica observada nos indivíduos idosos.

Segundo Beverley \& Douek ${ }^{22}$ e Koup, ${ }^{23}$ no timo ocorre substituição progressiva dos espaços perivasculares por tecido adiposo, restando uma proporção mínima de tecido cortical ou medular. Além disto, em animais idosos é verificado que as células T virgens remanescentes são defeituosas, produzem menor nível de citocinas e, portanto, apresentam menor atividade proliferativa e baixo potencial de diferenciação em células T efetoras. ${ }^{24}$

Este fato contribui para a baixa resposta imune aos antígenos vacinais e para a reduzida geração de memória imunológica, o que conseqüentemente leva a reduzidos níveis de proteção das vacinas verificados nos idosos. A diferenciação das células T virgens em células $\mathrm{TCD}^{+}$e/ou $\mathrm{TCD}^{+}$é crucial para a erradicação de um patógeno invasor, como por exemplo, o vírus da influenza, uma vez que os mecanismos efetores são ativados e inúmeras citocinas pró-inflamatórias são secretadas. De acordo com Di Genova et al. ${ }^{25}$ através da ativação via células apresentadoras de antígenos (APCs) ou pela secreção de citocinas, tais como IL-2, IL-4 e IL-5, as células $\mathrm{TCD}^{+}$efetoras estimulam a resposta das células B e aumentam o desenvolvimento de células TCD8 ${ }^{+}$.

Outro fator envolvido na redução da resposta imune observado durante o envelhecimento está relacionado com a alta produção de auto-anticorpos. Para Novaes et al., ${ }^{26}$ os níveis elevados destes anticorpos estão diretamente associados à maior susceptibilidade da po- pulação de idosos a doenças infecciosas e à baixa capacidade protetora das vacinas.

Conforme demonstrado no estudo de Weksler \& Goodhardt, ${ }^{27}$ na medida em que os organismos vivos envelhecem, mudanças qualitativas na reposta imune humoral ocorrem, passando de altamente específicas contra antígenos estranhos, para mais específicas contra antígenos próprios. Para os autores, a perda gradual da capacidade de discriminação de antígenos estranhos estaria associada a um aumento na produção de auto-anticorpos naturais, ocasionando uma diminuição da produção de plasmócitos e, conseqüentemente, da produção de anticorpos nominais. ${ }^{27}$

De acordo com Novaes et al. ${ }^{26}$ durante o envelhecimento as perdas preferencialmente de anticorpos da classe IgG e de anticorpos de alta afinidade estão estritamente relacionadas com o aumento da susceptibilidade aos processos infecciosos e da severidade de diversas doenças, assim como com a menor eficiência das vacinas.

\section{O USO DE ADJUVANTES NA VACINAÇÃO DO IDOSO}

Diante do exposto, percebem-se as conseqüências do envelhecimento sobre a resposta imunológica dos indivíduos, as quais levam a uma queda significativa da resposta a diversas imunizações e a um número elevado de mortes entre os idosos, devido ao desenvolvimento de doenças infecciosas. Além do acometimento de doenças tais como aterosclerose, doença de Alzheimer, diabetes mellitus e osteo- 
porose, resultado da gama de alterações que o sistema imune sofre durante o envelhecimento, ${ }^{28}$ a população de idosos sofre com os níveis baixos de proteção de inúmeras vacinas, o que faz com que atenção especial seja requerida em relação aos aspectos imunológicos típicos da imunossenescência e à necessidade de estratégias de vacinação que melhoram a eficiência das vacinas.

Vários mecanismos baseados na adição de adjuvantes às formulações vacinais estão sen- do estudados, a fim de aumentar a eficiência da resposta imune do idoso a vacinações, bem como estimular a indução de memória imunológica duradoura relacionada às células $\mathrm{T} e$ $\mathrm{B}$ e secreção de anticorpos pelos plasmócitos, que em conjunto minimizam os efeitos adversos da imunossenescência. Os principais adjuvantes são divididos em dois grupos: os utilizados no sistema "antígenos associados a partículas" e os adjuvantes imunoestimulatórios. Destes, os mais utilizados são sumarizados na tabela 2 .

Tabela 2 - Tipos de adjuvantes atualmente estudados. Ouro Preto, MG, 2007.

\begin{tabular}{ll}
\hline Grupos de Adjuvantes & Principais Adjuvantes \\
\hline $\begin{array}{l}\text { Sistema “antígenos } \\
\text { associados a partículas" }\end{array}$ & Hidróxido de alumínio $[\mathrm{Al}(\mathrm{OH}) 3]$ ou fosfato de alumínio [AlPO4 $]^{29}$ \\
& Complexo imunoestimulatório (ISCOM $)^{30}$ \\
& Lipossomas ${ }^{31}$ \\
& Emulsão de microfluido $59(\mathrm{MF} 59 \mathrm{wa})^{32}$ \\
& $\begin{array}{l}\text { AS02Aw (um adjuvante óleo-em-água baseado em um lipídeo } \\
\text { monofosforil A (MPL) e do componente Quillaja saponaria 21) }\end{array}$ \\
& Oligodesoxinucleotídeo contendo motivos CpG (CpG-ODNs) ${ }^{34,35}$ \\
& $\begin{array}{l}\text { IC31w (uma combinação entre o oligodesoxinucleotideo 1 (OND1) e } \\
\text { um peptídeo antimicrobial (KLK) })^{35}\end{array}$ \\
& Citocinas ${ }^{36}$
\end{tabular}

De um modo geral, os adjuvantes imunoestimulatórios, através dos receptores toll-like (TLR) ou dos receptores de citocinas, estimulam o desenvolvimento das células dendríticas (CD), as quais passam a secretar distintas citocinas e a aumentar a expressão de moléculas do complexo de histocompatibilidade (MHC) e de moléculas co-estimulatórias, potencializando a resposta imune do idoso. Já os adjuvantes utilizados no sistema "antígenos associados a partículas" aumentam a apresentação de antígenos na ausência de moléculas co-estimulatórias, levando a uma forte resposta de células $B$ e a uma resposta do tipo Th2. ${ }^{37}$ 


\section{CONSIDERAÇOES FINAIS}

Nesta casuística, a qual se refere ao rápido e intenso crescimento do número de idosos, e diante do fato de que naturalmente este grupo etário é altamente susceptível a inúmeras doenças infecciosas, o poder público se depara com um grande desafio: a implementação de políticas que beneficiem os idosos, para que os anos conquistados a mais sejam vividos, sobretudo, com qualidade.

Conforme apresentado neste trabalho, diversos são os estudos que demonstram a reduzida resposta imune dos idosos a vacinas. Entretanto, mesmo levando em consideração o fato de que a idade interfere na geração de uma resposta imune eficiente, as vacinações constituem um dos mais importantes procedimentos médicos que previnem a morbidade e a mortalidade causada por diversas doenças infecciosas, incluindo a população idosa.

Neste sentido, o entendimento sobre os aspectos envolvidos na geração de uma memória imunológica duradoura no idoso e de como estes aspectos são afetados pelo processo do envelhecimento, provê uma base para o desenvolvimento de vacinas diferenciadas, capazes de proteger mais eficientemente a população de idosos contra inúmeras doenças infecciosas.

A importância de uma vacinação eficaz fica clara quando se analisam os números referentes às internações hospitalares de indivíduos idosos nos hospitais públicos do Brasil, vítimas de doenças infecciosas que muitas vezes poderiam ser evitadas com a ampliação da eficácia das imunizações. A partir de campanhas de imunização mais eficientes, um considerável número de internações e mortes por doenças respiratórias em idosos pode ser reduzido. Embora o país seja um dos que mais investem dinheiro público na cobertura vacinal de idosos, até o momento um percentual de $26 \%$, relativo aos recursos de internação hospitalar no Sistema Único de Saúde (SUS), é utilizado pela população de idosos ${ }^{10}$ o que representa um dado significativo, considerando-se as dimensões do país.

Através do desenvolvimento de estudos que visam a elucidar estratégias que melhoram a resposta imune do idoso a imunizações, como os relacionados ao uso de adjuvantes vacinais, melhorias na qualidade de vida dos indivíduos poderão ser observadas. É imprescindível que estudos envolvendo esses propósitos sejam estimulados, visto que a prevenção de enfermidades que interferem nas atividades rotineiras da população idosa reduz a morbidade e mortalidade por doenças infecciosas "imunopreveníveis", levando à garantia prioritária da qualidade de vida dos idosos.

Mais do que nunca, é necessário haver uma parceria sólida e estável entre as instituições que tratam da saúde do idoso, a fim de que o aumento da expectativa de vida das pessoas esteja intimamente ligado à melhoria da qualidade de vida da população em geral. O envelhecimento "bem-sucedido" deve ser uma meta, já que o bem-estar da população deve prevalecer sobre as severas condições de vida em que muitos idosos se encontram. 


\section{REFERÊNCIAS}

1. Wick $G$, et al. Diseases of Aging. Vaccine. 2000; 18:1567, 2000.

2. Fundação Instituto Brasileiro de Geografia e Estatística (IBGE). Diretoria de Pesquisas, Censos Demográficos. [citado em 2007 Set 21]. Disponível em: http:// www.ibge.gov.br.

3. Castle SC. Clinical relevance of age-related immune dysfunction. Clin Infect Dis. 2000; 31:578-585.

4. Berger R, Florent G, Just M. Decrease of the lymphoproliferative response to varicellazoster virus antigen in the aged. Infect Immun. 1981; 32:24-27.

5. Nagami PH, Yoshikawa TT. Tuberculosis in the geriatric patient. J Am Geriatr Soc. 1983; 31:356-363.

6. McVoy MA, Adler SP. Immunologic evidence for frequent age-related cytomegalovirus reactivation in seropositive immunocompetent individuals. J Infect Dis. 1989; 160:1-10.

7. Gardner EM, et al. Age-related changes in the immune response to influenza vaccination in a racially diverse, healthy elderly population. Vaccine. 2006; 24:1609-1614.

8. Herndler-Brandstetter D, Cioca DP, GrubeckLoebenstein B. Immunizations in the elderly: do they live up to their promise? Wien Med Wochenschr. 2006; 156:130-141.

9. World Health Organization (WHO). Global Immunization. [citado em 2004]. Disponível em http://www.who.int/ immunization_monitoring/data/.

10. Ministério da Saúde, Secretaria de Vigilância em Saúde, Departamento de Vigilância Epidemiológica, Coordenação Geral do Programa Nacional de Imunizações. Informe técnico. Brasília: Ministério da Saúde; 2006.
11. Levine MM, Sztein MB. Vaccine development strategies for improving immunization: the role of modern immunology. Nat Immunol. 2004; 5:460-464.

12. Plotkin SA. Vaccines: past, present and future. Nat Med. 2005; 11:S5-11.

13. Lambert PH, Liu M, Siegrist CA. Can successful vaccines teach ushowto induce efficient protective immune responses? Nat Med. 2005; 11:S54-62.

14. Muszkat M, et al. Local IgA response following administration of a novel intranasal inactivated influenza virus vaccine in community residing elderly. Vaccine. 2000; 18:1696-1699.

15. Goodwin K, Viboud C, Simonsen L. Antibody response to influenza vaccination in the elderly: a quantitative review. Vaccine. 2006; 24:1159-1169.

16. Cook JM, et al. Alterations in the human immune response to the hepatitis B vaccine among the elderly. Cell Immunol. 1987; 109:89-96.

17. Hainz U, et al. Insufficient protection for healthy elderly adults by tetanus and TBE vaccines. Vaccine. 2005, 23:3232-3235.

18. Haynes L, Swain SL. Whyaging Tcells fail: implications for vaccination. Immunity. 2006; 24:663-666.

19. Musher DM, et al. Natural and vaccine-related immunity to Streptococcus pneumoniae. J Infect Dis. 1986; 154:245-256.

20. Aspinall R, Del Giudice G, Effros RB, Grubeck-Loebenstein B, Sambhara S. Challeneges for vaccination in the elderly. Immunity \& Ageing. 2007; 4:9.

21. Malaguarnera L, et al. Immunosenescence: a review. Arch Gerontol Geriatr. 2001; 32:1-14.

22. Beverley PC, Grubeck-Loebenstein B. Is immune senescence reversible? Vaccine. 2000; 18(16):1721-4. 
23. Douek DC, Koup RA. Evidence for thymic function in the elderly. Vaccine. 2000; 18(16):1638-41.

24. Stacy S, Krolick KA, Infante AJ, Kraig E. Immunological memory and late onset autoimmunity. Mech Ageing Dev. 2002;123(8):975-85.

25. Di Genova G, et al. Vaccination of human subjects expands both specific and bystander memory $\mathrm{T}$ cells but antibody production remains vaccine specific. Blood. 2006; 107:2806-2813.

26. Novaes MRCG, Ito MK, Arruda SF, Rodrigues P, Lisboa AQ. Micronutrients supplementation during the senescence: implications for the immunological functions. Rev. Nutr. 2005; 18(3):367:376

27. Weksler ME, Goodhardt M. Do ageassociated changes in "physiologic" autoantibodies contribute to infection, atherosclerosis, and Alzheimer's disease? Exp Geront. 2002; 37(8-9):971-9.

28. Westendorp RG. What is healthy aging in the 21 st century? Am J Clin Nutr. 2006; 83:404S409S.

29. Brewer JM. (How) do aluminium adjuvants work? Immunol Lett. 2006; 102:10-15.

30. Sjolander A, Cox JC, Barr IG. ISCOMs: an adjuvant with multiple functions. J Leukoc Biol. 1998; 64:713-723.
31. Kovar M, et al. Direct stimulation of T cells by membrane vesicles from antigenpresenting cells. Proc Natl Acad Sci U S A. 2006; 103:11671-11676.

32. Podda A, Del Giudice G. MF59-adjuvanted vaccines: increased immunogenicity with an optimal safety profile. Expert Rev Vaccines. 2003; 2:197-203.

33. Vandepapeliere P, et al. Potent enhancement of cellular and humoral immune responses against recombinant hepatitis $\mathrm{B}$ antigens using AS02A adjuvant in healthy adults. Vaccine. 2005; 23:2591-2601.

34. Krieg AM. Therapeutic potential of Tolllike receptor 9 activation. Nat Rev Drug Discov. 2006; 5:471-484.

35. Schellack C, et al. IC31, a novel adjuvant signaling via TLR9, induces potent cellular and humoral immune responses. Vaccine. 2006; 24:5461-5472.

36. Kutzler MA, et al. Coimmunization with na optimized IL-15 plasmid results in enhanced function and longevity of CD8 $\mathrm{T}$ cells that are partially independent of CD4 T cell help. J Immunol. 2005; 175:112-123.

37. Kovaiou DD, Herndler-Brandstetter D, Grubeck-Loebenstein B. Age-related changes in immunity: implications for vaccination in the elderly. Expert Rev. Mol. Med. 2007; 9:1-17. 
1 